\title{
New genomes clarify mimicry evolution
}

\section{Citation}

Mallet, James. 2015. “New Genomes Clarify Mimicry Evolution." Nature Genetics 47 (4) (March 27): 306-307. doi:10.1038/ng.3260.

\section{Published Version}

doi:10.1038/ng.3260

\section{Permanent link}

http://nrs.harvard.edu/urn-3:HUL.InstRepos:25290367

\section{Terms of Use}

This article was downloaded from Harvard University's DASH repository, and is made available under the terms and conditions applicable to Other Posted Material, as set forth at http:// nrs.harvard.edu/urn-3:HUL.InstRepos:dash.current.terms-of-use\#LAA

\section{Share Your Story}

The Harvard community has made this article openly available.

Please share how this access benefits you. Submit a story.

Accessibility 
News \& Views:

\section{New butterfly genomes clarify mimicry evolution}

[Pre-publication version. A heavily edited version was published as: Mallet, J. (2015). "New genomes clarify mimicry evolution." Nature Genetics 47(4): 306-307. ] http://www.oeb.harvard.edu/faculty/mallet/publications.html

James Mallet

For over 100 years it has been known that mimicry polymorphisms are often switched by simple Mendelian factors. Yet the physical nature of these loci has hitherto escaped characterization. The sequencing of two swallowtail butterfly (Papilio) genomes marks the latest episode of an extraordinary few years of discoveries in mimicry genetics.

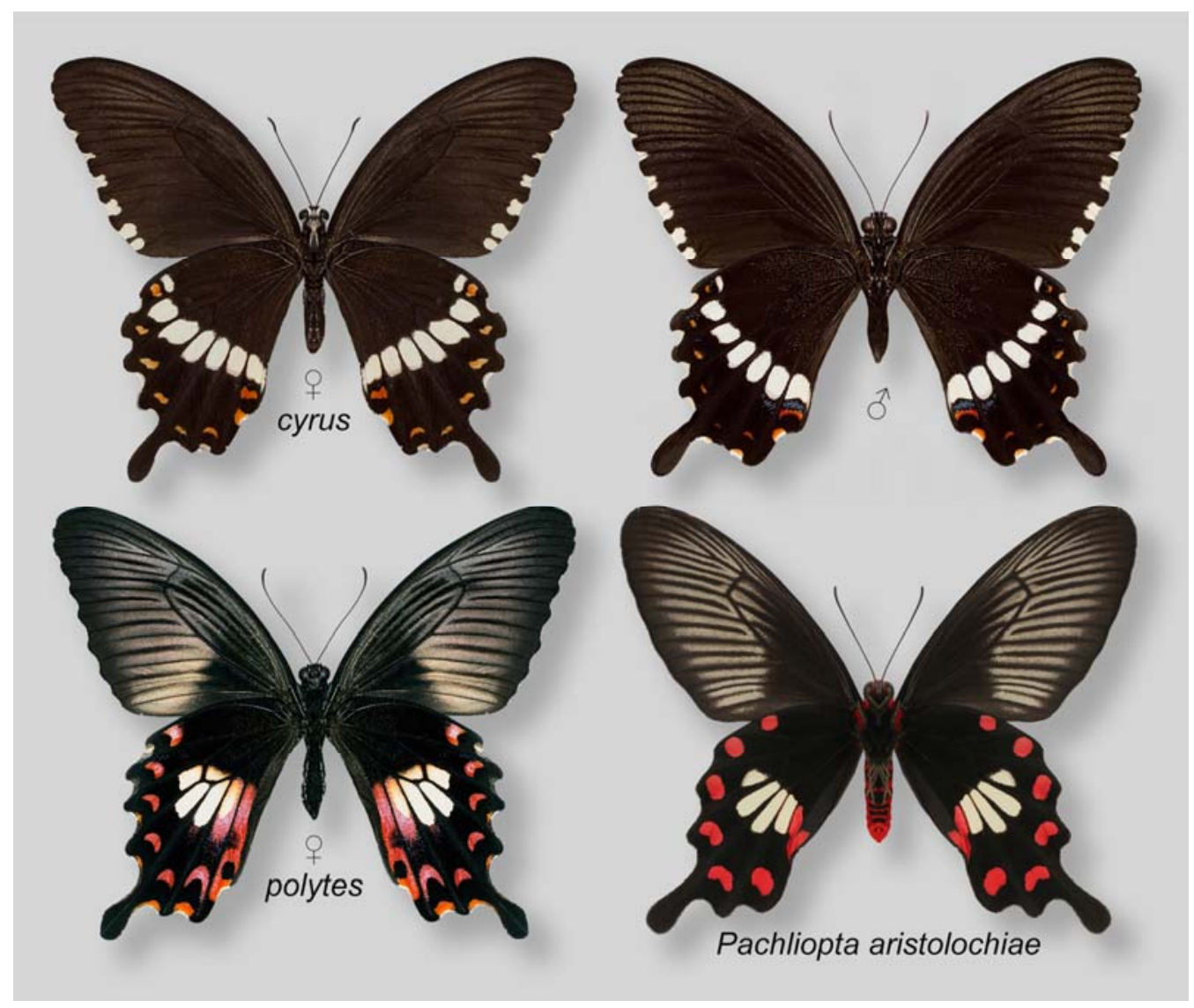

Figure 1. Mimetic and non-mimetic Papilio polytes and its noxious model Top row: non-mimetic form and male; bottom row: mimetic female and the noxious model species, Pachliopta aristolochiae. (Krushnamegh Kunte (C 2015).

Non-poisonous butterflies that mimic noxious species are "cheats:" their colour patterns lie about their toxicity. One example is the swallowtail butterfly Papilio polytes. Females occur either as a male-like, black-and white form which is non-mimetic, or as a red-spotted form that mimics a poisonous 
species, Pachliopta aristolochiae (Fig. 1). On p. 405 of this issue, Haruhiko Fujiwara and colleagues report the genome sequences of Papilio polytes and a close relative, $P$. xuthus. They convincingly show that mimicry in $P$. polytes is effected by a single gene, doublesex $(d s x)^{1}$.

This work joins a flurry of recent genomic work on mimicry in P. polytes and other butterflies ${ }^{2-6}$, which together bring us much closer to understanding how mimicry works.

\section{Characterization of a mimicry supergene}

Decades ago, it was hypothesized that mimicry switch loci might consist of multiple, tightly linked genes, collectively acting as a "supergene"7. In 2014 the so-called $H$ locus (the mimicry switch gene) of a Philippines population of $P$. polytes was shown to consist of an allele of $d s x$ within a small $\sim 130 \mathrm{~kb}$ inversion ${ }^{5}$. This finding was too bizarre to have been predicted: $d s x$ is a highly conserved transcription factor involved in sex-determination of both protostomes and deuterostomes. How on earth could such an important gene be co-opted to twiddle with colour patterns late in the development of the wing of an adult butterfly? The finding was surprising in another way. Rather than a collection of genes being contained in the mimicry "supergene", it appeared that coding changes in and perhaps non-coding regions near $d s x$ itself were responsible.

Last year's paper was astounding enough, but it is now evident that Fujiwara's group was working independently on the same problem in a different population of Papilio polytes. Indeed, they had already hinted that they had tracked the $H$ locus to a sex-determination gene ${ }^{8}$. The current paper ${ }^{1}$ raises the bar for mimicry publications: the $d s x$ locus is characterized in much greater detail to show that both inversion breakpoints are located within a few base pairs of each other. In addition, two new Papilio whole genome assemblies, as well as fosmid clone sequences covering the $d s x$ region, are thrown in for good measure. For the first time, the function of $d s x \_H$ is proved in mimicry: small interfering RNAs (siRNA) designed to knock down $d s x_{-} H$ repressed mimetic phenotypes in the mimetic form; in contrast, $d s x \_h$ knockdown failed to suppress mimetic patterning. Fujiwara et al. infer that shows that the "default" male-like colour pattern is determined by genes elsewhere in the genome, with little involvement from $d s x$. The $d s x \_H$ allele acts by switching those genes to make a different female pattern.

The system's surprising flexibility may be due to modularity within Dsx; only some peptide domains are highly conserved and required in sex-switching and DNA binding. Another layer of modularity is due to alternative splicing of $d s x$ transcripts: in Papilio there is a single male isoform, but three different 
female isoforms, each of which can be expressed differentially, between body and wings, for example ${ }^{5}$. These findings give a glimmer of understanding as to how the central function of $d s x$ in primary sex determination, such as ovary and testis development, may be detached from later activity in colour pattern development of the adult wing surface ${ }^{5}$.

The $d s x \_H$ allele is the most highly divergent $100 \mathrm{~kb}$ region of DNA $(\sim 25 \%)$ in the whole $P$. polytes genome. This nucleotide divergence is presumably maintained by balancing selection acting on multiple sites in $d s x$, while its private inversion inhibits recombination. There are around 20 or so coding differences between $d s x \_h$ and $d s x_{-} H$ in both India and Japan. However, only five of these differences are specific to $d s x_{-} H$ compared with other nonmimetic Lepidoptera ${ }^{1}$. The other coding differences may represent real differences in patterning between The Philippines and Okinawa, or they may be hitch-hiking variants of little importance. The many non-coding differences likely include some that have non-coding RNA or cis-regulatory functions.

\section{Controversies about mimicry}

This year marks the centenary of a long-standing genetic controversy about mimicry. Not long after the rediscovery of Mendel, in 1915 Reginald Punnett ${ }^{9}$ demonstrated that mimicry in P. polytes and other Papilio was switched simply by a single dominant allele, $H$. In the first ever population genetic analysis of natural selection, Punnett showed that directional selection should quickly fix polymorphic variants. He concluded that long-lived polymorphisms, as in $P$. polytes, could not be under selection, and that mimicry arose as a neutral large-effect mutation of the $H$ locus.

Mimicry became a cause célèbre of the Modern Synthesis of Darwinism and Mendelism in the 1930s-1970s. Ronald A. Fisher devoted a whole chapter of his ground-breaking book 10 to mimicry, to promote Darwinian gradualism and rebut the earlier Mendelians' ideas. Punnett did not know about balancing selection, which Fisher discovered soon after. Fisher proposed that mimetic polymorphisms could be stable due to frequency-dependent selection: as "cheats" became common, their mimicry would be rumbled by predators and the advantage lost, leading to equilibrium. He argued that perfect mimicry necessarily involved gradual adjustment of many pattern elements, surely requiring multiple genetic loci. Polymorphism in P. polytes and other mimics was switched by a single locus, but the system had to depend on multiple interacting "modifiers" scattered throughout the rest of the genome to fine tune dominance and control by the switch locus itself, giving seamless transitions between adaptive forms. In Papilio, the $H$ locus would thereby be able to transition between male-like and mimetic females without disadvantageous intermediates. 
Later, crosses of P. polytes and other Papilio species by Cyril Clarke and Philip Sheppard largely supported Fisher's views on multifactorial inheritance, but added the new idea that some of the loci may be prevented from recombining via tight linkage in a "supergene." In Papilio dardanus and P. polytes, Cyril Clarke and Philip Sheppard showed that crosses between geographically distant populations, but not local populations, tended to produce intermediate and poorly adapted forms ${ }^{11}$. They concluded that linked sites and unlinked modifiers elsewhere in the genome diverged in different localities, and were being perfected for interaction only with the local switch gene, as suggested by Fisher. While Clarke \& Sheppard provided excellent evidence for involvement of multiple genetic changes in the mimicry switches, in those pre-molecular-marker days, the mode of action of mimicry "supergenes" was still murky.

In the last couple of years, we've learned a lot more. But we're still ignorant of which of the many differentiated sites in the $d s x \_H$ region are effectors of mimicry. Furthermore, there are intriguing expression differences for $d s x \_h$, $d s x_{-} H$, and their isoforms, and even for some genes just outside the $d s x$ inversion 1,5 . We are only beginning to understand how $d s x$-based sex determination in Lepidoptera differs from that in Drosophila12, and we know none of the downstream targets of $d s x$ in colour pattern pathways. The latest findings in Papilio polytes ${ }^{1,5}$ revolutionize our understanding of the genetics and evolution of mimicry, but we still have a way to go before we'll fully grasp this extraordinary adaptation.

1. Nishikawa, H. et al. Genome structure and molecular mechanism underlying female-limited polymorphic mimicry. Nature Genetics xxx, 000 (2015).

2. Reed, R.D. et al. optix drives the repeated convergent evolution of butterfly wing pattern mimicry. Science 333, 1137-1141 (2011).

3. Martin, A. et al. Diversification of complex butterfly wing patterns by repeated regulatory evolution of a Wnt ligand. Proceedings of the National Academy of Sciences, USA 109, 12632-12637 (2012).

4. Gallant, J.R. et al. Ancient homology underlies adaptive mimetic diversity across butterflies. Nature Communications 5, 4817 (2014).

5. Kunte, K. et al. doublesex is a mimicry supergene. Nature (London) 507, 229-232 (2014).

6. Timmermans, M.J.T.N. et al. Comparative genomics of the mimicry switch in Papilio dardanus. Proceedings of the Royal Society B: Biological Sciences 281, 20140465 (2014).

7. Turner, J.R.G. Mimicry: the palatability spectrum and its consequences. (eds. Vane-Wright, R.I. \& Ackery, P.R.) 141-161 (Academic Press, London, 1984).

8. Nishikawa, H. et al. Molecular basis of wing coloration in a Batesian mimic butterfly, Papilio polytes. Scientific Reports 3, 3184 (2013).

9. Punnett, R.C. Mimicry in Butterflies, vii + 188 pp (Cambridge University Press, Cambridge, 1915).

10. Fisher, R.A. The Genetical Theory of Natural Selection, - (Clarendon Press, Oxford, 1930). 
11. Clarke, C.A. \& Sheppard, P.M. The genetics of the mimetic butterfly Papilio polytes.

Philosophical Transactions of the Royal Society of London Series B-Biological Sciences 263, 431-458 (1972).

12. Nagaraju, J., Gopinath, G., Sharma, V. \& Shukla, J.N. Lepidopteran sex determination: a cascade of surprises. Sexual Development 8, 104-112 (2014). 